\title{
Role of general and local antibiotic prophylactic in hernia repair
}

By

Specialist surgean Dr. Ihsan Ali Mohammed ${ }^{* 1}$; Specialist surgeon

\section{Dr. Arkan kareem abd Al salami ${ }^{* 2}$}

${ }^{* 1}$ M.B.CH.B , M.R.C.S Ireland* AL-Yarmook Teaching hospital , Minstry of health and enviroment $/{ }^{* 2}$ M.B.CH.B , FICMS, AL-Yarmook Teaching hospital, Minstry of health and enviroment -Baghdad ,Iraq

*Correspondent authur : Dr. Ihsan Ali Mohammed

D.O.I - 10.51201/JUSST/21/05165

http://doi.org/10.51201/JUSST/21/05165

\section{Abstract :}

The current study was designed to evaluate the effect of using prophylactic antibiotic in preventing wound infection post operatively in patients with non recurrent hernia surgery.A prospective study of 180 patients with inguinal hernia where divided into three groups -:first group of 90 patients were operated on with administration of three dose of ( third generation) cephalosporin.first dose given perioperatively Second dose given eight hours post operatively later.third dose given 24 hour post operatively later, Second group 40 patients local Garamycine $80 \mathrm{MG}$ diluted in 250 saline solution was used to wash the wound of each patients, third group fifty patients (27.7\%) patients were remain without any antibiotic post operatively.observation of all patients regarding site of surgery were done till ten days after removal of stitches, so Wound swab were taken whenever any signs of infection begin to show on wound and send for culture and drug sensitivity.result :wound infection was occur $5.5 \%$ (five patients ) out of ninety patients in the first group while it occur in $2.5 \%$ (one patients) in the second group and in the third group 6\% ( three patients) conclusion :no difference in infection rate weather the patients receive prophylactic antibiotic or not . there is less infection by using local antibiotic in comparison with other two groups but this difference is not statically significant p-value(0.7082)

Keyword: Hernia ;SSI (surgical sit infection ); antibiotic prophylactic ;hernia repair 


\section{Introduction}

In walking the abdomen becomes taut amount to an Achilles heels tissue and organ easily slip though defects in supporting adnominal structure in accordance to this fact hernia repair in the most common type of general surgical operation perform today $(1,3,4)$

Surgical site infection is an annoying complication for both surgean and patient consume time and money ${ }^{(21}$ ) , Edoardo Bassimi 1844-1924 preformed the first hernia repair 1984 and published study on this field focus on one infection in the rate of $5.3 \%^{(5,3)}$

Inguinal hernia repair is a clean surgical procedure and surgical site infection in generally low but if it occur following herniorrhaphy it regard as potent cause of recurrence of hernia if it occur deep to external obligue aponeurosis. Most of wound infection reveal on the end of first week postoperatively between three and seven days. ${ }^{(6)}$

There are many factors affecting the incidence of infection may be intrinsic local like hematoma, infection in groin region ${ }^{(8,7)}$, Or intrinsic general like advance age defect in immune system which may be due to disease of drug induce, poor nutritional status, Diabetes mellitus, renal failure, liver disease, etc. ${ }^{(8,7)}$,Others said that record of incidence of infection of $4 \%{ }^{(9)}$.

Although hernia repair is considered clean surgery with 1-3\% rate of wound sepsis ${ }^{(6,9)}$ still some surgeons give antibiotic prophylaxis, other do not because they believe that (it is a clean surgery and increase in number of risk factors not greatly influence the rate of postoperative infection). ${ }^{(6,10)}$

\section{Materials and methods:}

From april 2012 to april 2014 ,180patients of different age groups with inguinal hernia were subjected to elective herniorrhaphy in al - yarmouk teaching hospital. The repair was achived by DARN method herniorraphy,inwhich repair of herenial defect is done by :-

Using Nylon 0 and vicryl 0 to repair posterior wall of inguinal canal for 52 patients (28,9/), and 128 patients ( $71.1 \%$ ) the repair achives by using prolene mesh

\section{The patients are divided into 3 groups:}


First group are (90 ) patients(50\%), (of them 63 patientshad got mesh repair , and 27 without ), were given acording to their body wt (50 MG/ KG ) adose of $1 \mathrm{~g}$ of cefetraxsone periopreativly, anther dose 8 hours postopreativly, 3rd dose after 24 hour after ,take all precautions that patients had no history of drug allergy to cephalosporine .

The second group 40 patient (22,2\% ) (of them 28 had got hernial repair by mesh , and 12 patients without mesh ) were given local sub facial irrigation of mixture of $80 \mathrm{mg}$ of Garamycine diluted in $250 \mathrm{ML}$ of normal saline during closure of wound .

3rd group 50 patients ( 27,7\% ), of them 37 (74\%) patients with mesh repair , and 13 (26\% )without,NO patient received any type of antibiotic . All patients were examined generally and subjected to routine anasthetic pre op cheek up , also for local examination ; prior to discharge , and as outpatient at 7th day post opreativly, before removal of stitches with instructions given to be seen in between the two situation in case of any sign of infection appeared in the wound like reddness of skin edges , swelling, pain, and discharge , since most of wounds infection become apparent at end of frist week following surgury, but use of prophylaxsis might dealy it (7). Wound swabs taken from patients with infected wound and send for culture to identify the organism . Furthermore we assess any possible risk factor patient he might have .

\section{Results :}

Table (1): Distribution of patients with inguinal hernia according to Age groups and wound infections.

\begin{tabular}{|l|l|l|}
\hline \multicolumn{1}{|c|}{ No. of group } & \multicolumn{1}{|c|}{ Age group ( years) } & Number of patients(\%) \\
\hline Group 1 & $>30$ & $25(13.8)$ \\
\hline Group 2 & $30-40$ & $37(20.5)$ \\
\hline Group 3 & $40-50$ & $48(26.6)$ \\
\hline Group 4 & $50-60$ & $42(23.3)$ \\
\hline Group 5 & $<60$ & $38(21.1)$ \\
\hline Total & $180(100)$ \\
\hline Group number & $\begin{array}{l}\text { Number of cases with SSI } \\
*\end{array}$ \\
\hline First Group & general prophylaxsis & 5 cases (5.5\%) \\
\hline Second Group & local prophylaxsis & 1 cases $(2.5 \%)$ \\
\hline Third Group & no prophylaxsis & $3(6 \%)$ \\
\hline Total & 9 cases \\
\hline
\end{tabular}

* SSI (surgical sit infection ) 
The age distribution of all patients with inguinal hernia is shown in table (1), The high percentage of patients in Group 3 (26.6\%) was significantly higher than in Groups 4 (23\%) and 5 (21\%). As well as this table shows distributions of cases who got SSI, according to whether the patient receive general local antibiotic; or not receive any type of prophylaxis antibiotics . so the group with the use of topical antibiotic had the lowest incidance $(2.5 \%)$ in our study. Also not statically significant p-value(0.7082)

Table (2): Types of genral risk factor patient with hernia suferring from it

\begin{tabular}{|l|l|}
\hline Type of risk factors & Number of patients(\%) \\
\hline Obsity & $30(16.6 \%)$ \\
\hline Chest infection & $10(5.5 \%)$ \\
\hline Diabetes mellitus & $26(14.4 \%)$ \\
\hline Abnormal renal indices & $8(4.4 \%)$ \\
\hline Liver impairment & $3(1.66 \%)$ \\
\hline Immune compromise patient & $5(2,77 \%)$ \\
\hline Cutaneous infection & $1(0.55 \%)$ \\
\hline Total & 83 patients $(46.11 \%)$ \\
\hline
\end{tabular}

Table (2) show distributions of patients according to general seven risk factors (Obsity, Chest infection, Diabetes mellitus, Abnormal renal indices , Liver impairment, Immune compromise patient, Cutaneous infection).Of 83 patients with hernia , 16.6\% were Obsity, $14.45 \%$ were Diabetes mellitus, and $5.5 \%$ were Chest infection compare with Cutaneous infection and Liver impairment as ( $0.55,1.66) \%$ respectively.These genral risk factors might increase rate of infections.

Table (3): percentage of patients had hernial repair with mesh

\begin{tabular}{|l|l|l|l|}
\hline \multicolumn{5}{|c|}{ Patients hernial repair } \\
\cline { 1 - 3 } Groups & With mesh & With out mesh & \multirow{1}{*}{ (100) } \\
\hline First group & 63 & 27 & \\
\hline Second group & 28 & 12 & \\
\hline Third group & 37 & 13 & \\
\hline Total & $128(71.1 \%)$ & $52(28.9 \%)$ & \\
\hline
\end{tabular}


Results in table (3) show distributions of cases according to the use of mesh in hernia respire. so more than $(71.1 \%)$ had done hernioplasty (using mesh )rather than herniorraphy (direct suturing of posterior wall by nylon)

Table (4): Types of wound infection clinically assess .

\begin{tabular}{|l|l|}
\hline Types of Infection & NO.of patients \\
\hline Stich abcess & $4(44 \%)$ \\
\hline Discharge of pus & $5(56 \%)$ \\
\hline Total & $9(100 \%)$ \\
\hline
\end{tabular}

In table (4) show that the SSI in hrrnial surgery is most likly to be limited and varies between stich abcess (44\%) compare to local discharge of pus(56\%).

Table (5): clssification of wound infction according to bacterial isolate

\begin{tabular}{|l|l|l|l|}
\hline $\begin{array}{l}\text { Name of } \\
\text { bacterial isolate }\end{array}$ & $\begin{array}{l}\text { Prophylactic } \\
\text { antibiotic }\end{array}$ & $\begin{array}{l}\text { No antibiotic } \\
\text { prophylaxsis }\end{array}$ & Total \\
\hline $\begin{array}{l}\text { Staphylococcus } \\
\text { aureus }\end{array}$ & 3 & 3 & $6(66 \%)$ \\
\hline $\begin{array}{l}\text { Pseudomonas } \\
\text { aeruginosa }\end{array}$ & 3 & 0 & $3(34 \%)$ \\
\hline Total & 6 & 3 & $9(100 \%)$ \\
\hline
\end{tabular}

Table 5 show type of bacteria isolate isolated from infected wound. the most com men causative agent in wound infction is Staphylococcus aureus (66\%), followed by Pseudomonas aeruginosa(34\%).

Table (6): Distrbution of cases with incedence of infections according to using mesh repair

\begin{tabular}{|l|l|l|l|l|}
\hline No. & Mesh & No. of patients & infected & $\%$ \\
\hline 1 & With mesh & 128 & 8 & 6.25 \\
\hline 2 & Without mesh & 52 & 1 & 1.9 \\
\hline 3 & Total & 180 & 9 & 5 \\
\hline
\end{tabular}


In table 6 show the distrbution of cases with incedence of infection according to the use mesh as (6.25\%) or not ( without mesh $1.9 \%$ ). So these table show that using of mesh may increase rate of wound infections.

\section{Discussion}

Inour study,the incidance of wound infection following hernial repair amonge the whole number of patients (180cases)is 5\% (9patients).inguinal hernia repair is clean surgical procedure and surgical sit infection (SSI) is general low and antibiotic prophylaxsis is not routinly recommanded ,but it may be of good choice for cases with high rate of wound infection more than 5\%.most frustrating event in wound healing is breakdown of wound by infection since it prolonge hospital stay and predispose to recurance. ${ }^{(8,11)}$

There are many studies about the incidance of wound, A study of WERXHAM showed that wound infection occure in about $4,6 \%$ and wound haematomas in $4.3 \%{ }^{(11)}$, others give incidance of $1 \%$ even though the Incison carry high burdan of skin bacteria ${ }^{(6)}$, soMAINGOT show that wound infection occure in about $5 \%$ of inguinal hernia repair and perccntage is much less if we exclude minor redness of skin edges, discharge of some clean serous fluid or small stich clean abscess ${ }^{(5)}$, GOTTRUP shows incidance of wound infection $5 \%{ }^{(12) .}$

Different local factors effects wound infection in our study presence of mesh (surgical) has high infection rate 6.2\% (8 patients out of 128) while in non mesh surgical repair is $1.9 \%$ (one patient in out of 52 patients ), mesh repair become the procedure of choic in most centers and post mesh herniorraphy infection rate remain Un acceptable level in last 30 years ${ }^{(13) .}$ So the use of prostbetic mesh add extra problem , and may ultimatly need to be removed to control Iocal infection ${ }^{(13)}$.

Tension impedes microcirculation decrease tissuse oxygenation interferewith proper prolene and lysine normal collage fiber polymerization cross linking cannot occure and weak scare tissuse resulte.

That is why proper tissuse handling and approximation of tissuse edge In amanner of tension free specialy in teaching genral hospital like our hospital where a lot of junior surgean complete their post graduat training is an important foctor for devloping of clean stronge scare ${ }^{(11)}$.

Genral hospitals like our hospital who recive every kinds of surgical cases many have high rate of SSI $>5 \%^{(14,15)}$. In fact preventig of 
haematomas reduce wound infection rate in many kinds of surgicul procdurcs ${ }^{(16) .}$ In our study show that the infection improve by use local antibiotic , so use of local Garamycine 80mg diluted in 250 cc of normal saline has lower infection rate 2.5/ (one case in 40 patients ) while the rate seems to be not so much diffrent between group one (useof prophylactic genral antibiotic ) and that without prophylaxsis (5cases out of 90 patients ) in rate of 5.5/ , and 3 cases out of 50 cases in rate of 6/.

The benifit of topical antibiotic prophylaxsis is growing fact $\ln$ multipale surgical specialty including orthopedics , nurilogical , opthalmological , genral surguries ,However it use in inguinal hernial repair is limited ${ }^{(11,15,17)}$, Ryan reported the first paper about use of local penicillin in hernial surgury in $1967^{(18)}$, rat of infection was $5 /$. first paper about use of topical Garamycin in hernial repair published by Mssella and colleguse in $2001^{(17) \text {. }}$

Rate of infection was 0.3 / in comparisume with 2/ in control .DEYSINE also discribe use of local antibiotic following emprical suggestion from Dr. Wesly , ALExardar, they start to use wound irrgation by solution of Garamycin in normal saline, as apart of strict surgical protocol , he report aresult of 23 years work on 2006 .

The rate of infection was negligable by use of local pluse genral prophylaxsis, The major organizum isolated in our study is Staphylococcus aureus 60/ (6out of 9 patients with infected wound ), In other study the isolate this bacteria in 54/ of infected cases ${ }^{(8)}$, Most surgical wound infection occure due to implantation of organizum in tissuse at time of opreation which is mostly related to patient own flora ${ }^{(7)}$

\section{Conclusion :}

No difference in infection rate weather the patients receive prophylactic antibiotic or not . there is less infection by using local antibiotic in comparison with other two groups but this difference is not statically significant p-value(0.7082)

Ethical Clearance: None

Source of funding: None

Conflict of Interest: None

\section{Referenses :}

1-Samuel wilson SE . Groin hernias , postgraduate medicine , 1990,vol 87 / No.1 P:139-147 
2-Lewis D.C Inguinal Hernia repair in elderly, Journal of the Royal College of surgeons of Endinburgh, 1989, Vol 34 P:101-103 .

3- Malangoni MA, Rosen MJ.Hernias. In: CM Townsend, RD Beauchamp, et al. Sabiston Textbook of surgery, Philadlphia, PA: Elsevier, 2012:chap 46.

4- Chandon Das, Tahir Jamil etal., Abdominal wall hernias , Schwartz principal of surgury , 11e , chapter 37 ; inguinal hernias , 2019.

5- Gawrtzc BJ et al . HERNiAS, Moingots abdominal opreations 4th ed, prentice-Hell Int. Inc. , U.S.A , P:21 7-221 , 197 ,

6-NyhusL.M, CoNDon R.E, HERNIA, 3rd Edition , Philadiliphia , J. B LippincoTT company , 1989 P:301 -329

7-ArawnWallF. Et.al ,Harrison's principale of internal medicine 11th ed , 1987 , P: 485-490.

8 - Sherwood L.G. et.a. Manual of surgical infections, little Bcownaned company, Toranto 1 st ect. 1974 , p287-296.

9 - Bernard HR.cole WR. , Th prophylaxis of surgical infections. the effect of prophylaxis ant imicrobiel drugs on the incidence of the effect of unfection following potentially contaminated wound surgery 1964 . 64:151-173 .

10- Karren s , controversis in surgical sepsis , VoL . 1, Great Britain , 1980 P $83,110-125$.

11- Stoppa.R.E. Treatment of complicated groin and incisional hernias. World Journal of surgery, 1989, Vol. 13 P:545-554 .

12 - Cotturp f. Prevention of surgical -wound infections .N Engl J Med (2000) 342 (3):202-4. doi:10.1056/NEM200001203420310.

13- Deysine M.pathophysiology ,prevention,and management of prosthetic infections in hernia surgery .surg Clin North Am (1998)78(6):1105-15,viii.doi:10.1016/Soo39-6109(05)70372-8

14- Ergul Z ,Akinci M , Ugurluc, kulacoglu H ,yilmaz KBprophylactic antibiotic use in elective inguinalc hernioplasty in trauma center .henia (2012) 16 (2):145-51. dio :10 .1007/s10029-011-0881-2 
15- praveen S,Rohaizak M .Local antibiotics are equivalent to intravenous antibiotics in the prevention of superficial wound infection in inguinal hernioplasty .Asian J surg (2009) 32(1):59-63 doi:10.1016/S1015-9584(09)60011-7

16- Andersen JR ,Burcharth F ,Larsen HW ,Roder O ,Andersen B.polylycolic acid ,silk, and topical ampicillin their use in hernia repair and cholecystomy Arch surg (1980) 115(3):293-5. doi:10-1001/archsurg .1980 .01380030041009

17- Mussella M Guido A,Musella S .collagen tampons as aminoglycoside carriers to reduce postoperative in fection rate in prosthetic repair of doi:10-1080/110241501750070592

18- Ryan EA.Wound infection prevention by topical antibiotics . $\mathrm{Br} \mathrm{J}$ Surg(1967) 54 (5):324-9. doi:10.1002/bjs.1800540503

19- Deysine M.Infection control in a hernia clinic :24 year results of aseptic and antiseptic measure implementation in 4,620 "clean cases". Hernia (2006)10 (1) :25-9. doi:10.1007/s10029-005-0028-4

20- Junge K,Rosch R , klinge U „Krones C,Klosterhalfen B,Mertens PR ,et al.Gentamicin supplementation of polyvinylidenfluoride mesh materials for infection prophylaxis .Biomaterials(2005)26(7):787-93. doi:10.1016/j.biomaterials.2004.02.070

21-De Lissovoy G, Fraeman K, Hutchins V, Murphy D, Song D, Vaughn BB. Surgical site infection: incidence and impact on hospital utilization and treatment costs. Am J Infect Control (2009) 37(5):387-97. doi:10.1016/j.ajic.2008.12.010. 